\section{Efficacy of Magnetic Resonance Coronary Angiography}

Toru Miyoshi, MD; Toshio Honda, MD, PhD;

Fuminori Shinozuka;

Kazuhiko Sadamoto, MD, PhD;

Osamu Yamaguchi, MD, PhD

A 70-year-old man was diagnosed with transient ischemic attack, and a vulnerable plaque was observed in his carotid artery; hence, he was considered a vulnerable patient. Cardiac magnetic resonance angiography (MRA; Philips 3T Ingenia Elition X) was performed because the patient's electrocardiogram findings revealed an abnormal Q wave without any chest symptoms. The patient's cardiac MRA showed severe stenosis in the left circumflex branch (Figure A). Furthermore, non-contrast $\mathrm{T}_{1}$-weighted images (black blood) revealed high-intensity plaques (Figure B). The plaque-to-myocardial signal intensity ratio (PMR) was 4.00. Computed tomography (CT) of the heart at the same site revealed severe stenosis and positive remodeling. Later, coronary angiography demonstrated severe stenosis of the left circumflex branch (Figure C).

Cardiac magnetic resonance imaging (MRI) is a noninvasive technique that can be expected to produce images comparable to those of cardiac $\mathrm{CT},{ }^{1}$ and can identify vulnerable plaques. It has been reported that the rate of development of acute coronary syndrome within 2 years is $11 \%$ for patients with a PMR of $\geq 1.4 .^{2}$ In the present case, the region of interest value was almost the same on cardiac $\mathrm{CT}$, and plaque instability could not be identified; however, this suggests that MRI examinations are beneficial.

\section{References}

1. Kato S, Kitagawa K, Ishida N, Ishida M, Nagata M, Ichikawa $\mathrm{Y}$, et al. Assessment of coronary artery disease using magnetic resonance coronary angiography: A national multicenter trial. $J$ Am Coll Cardiol 2010; 56: 983-991.

2. Noguchi T, Kawasaki T, Tanaka A, Yasuda S, Goto Y, Ishihara $\mathrm{M}$, et al. High-intensity signals in coronary plaques on noncontrast T1-weighted magnetic resonance imaging as a novel determinant of coronary events. J Am Coll Cardiol 2014; 63: 989-999.

Received December 13, 2020; revised manuscript received January 4, 2021; accepted January 11, 2021; J-STAGE Advance Publication released online February 25, 2021 Time for primary review: 16 days

Department of Cardiology (T.M., T.H., F.S., O.Y.), Department of Neurosurgery (F.S., K.S.), Sadamoto Hospital, Matsuyama; Department of Cardiology, Pulmonology, Hypertension and Nephrology, Ehime University Graduate School of Medicine, Toon (T.M., O.Y.), Japan

Mailing address: Toru Miyoshi, MD, Department of Cardiology, Pulmonology, Hypertension and Nephrology, Ehime University Graduate School of Medicine, Shitsukawa, Toon 791-0925, Japan. E-mail: miyoshi.toru.kf@ehime-u.ac.jp

All rights are reserved to the Japanese Circulation Society.

For permissions, please e-mail: cj@j-circ.or.jp

ISSN-1346-9843

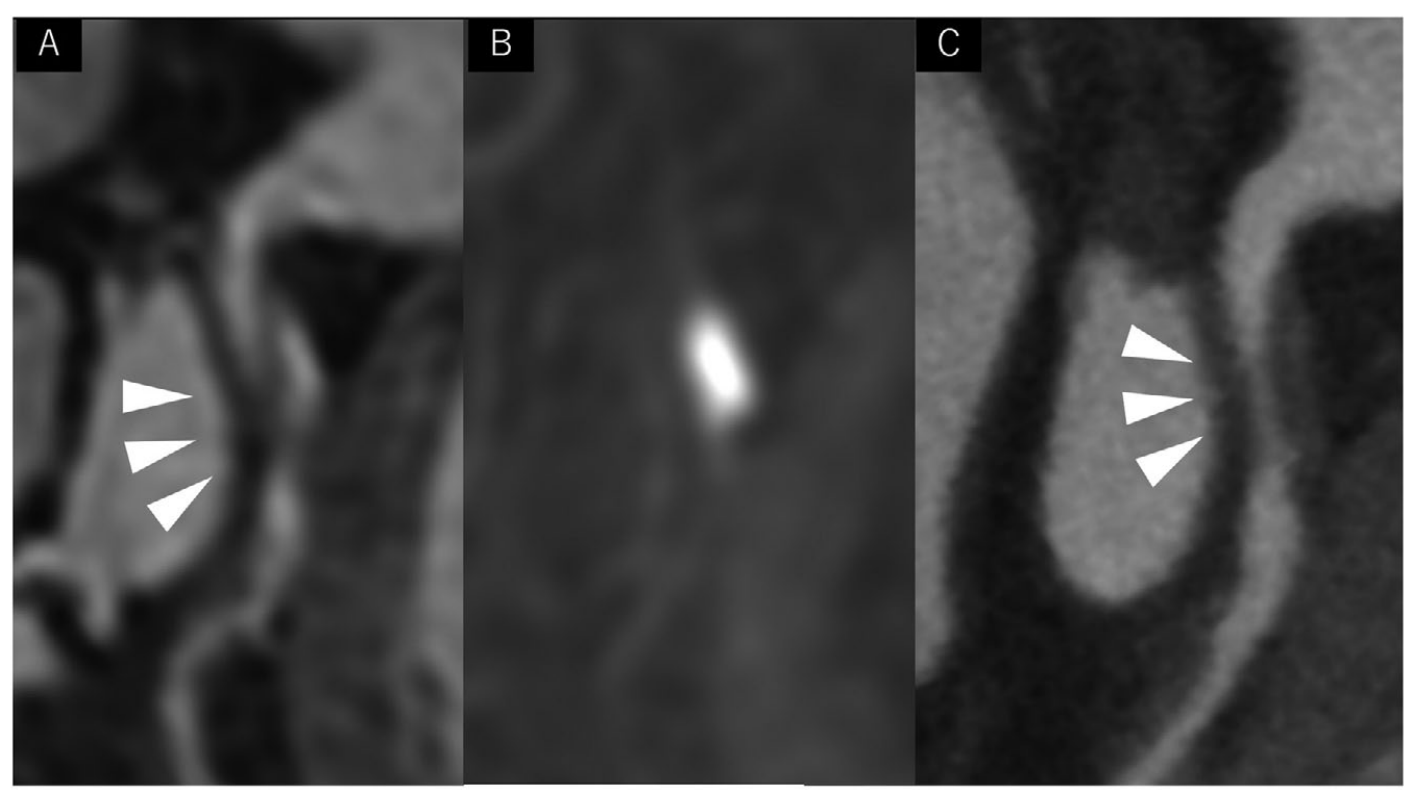

Figure. (A) Cardiac magnetic resonance angiography images. Severe stenosis is observed in the left circumflex branch (arrowheads). (B) Non-contrast T1-weighted image (black blood) findings. Note the high-intensity plaque. The plaque-to-myocardial signal intensity ratio was 4.00 . (C) Cardiac computed tomography images showed severe stenosis at the left circumflex artery (arrowheads). 